\title{
What can intraspecific trait variability tell us about fungal communities and adaptations?
}

\author{
Franz-Sebastian $\operatorname{Krah}^{1}$ (1) $\cdot$ Claus Bässler $^{1}$ \\ Received: 30 October 2020 / Revised: 22 March 2021 / Accepted: 3 May 2021 \\ (C) The Author(s) 2021
}

\begin{abstract}
Analyses of species functional traits are suitable to better understand the coexistence of species in a given environment. Trait information can be applied to investigate diversity patterns along environmental gradients and subsequently to predict and mitigate threats associated with climate change and land use. Species traits are used to calculate community trait means, which can be related to environmental gradients. However, while species traits can provide insights into the mechanisms underlying community assembly, they can lead to erroneous inferences if mean trait values are used. An alternative is to incorporate intraspecific trait variability (ITV) into calculating the community trait means. This approach gains increasing acceptance in plant studies. For macrofungi, functional traits have recently been applied to examine their community ecology but, to our knowledge, ITV has yet to be incorporated within the framework of community trait means. Here, we present a conceptual summary of the use of ITV to investigate the community ecology of macrofungi, including the underlying ecological theory. Inferences regarding community trait means with or without the inclusion of ITV along environmental gradients are compared. Finally, an existing study is reconsidered to highlight the variety of possible outcomes when ITV is considered. We hope this Opinion will increase awareness of the potential for within-species trait variability and its importance for statistical inferences, interpretations, and predictions of the mechanisms structuring communities of macro- and other fungi.
\end{abstract}

Keywords Community ecology $\cdot$ functional traits $\cdot$ community-weighted mean $\cdot$ fixed average $\cdot$ specific average $\cdot$ fungi $\cdot$ fruit body

\section{Introduction}

Climate change and land use dramatically affect the biodiversity within ecosystems (Fahrig 2003; Lindner et al. 2010). However, our restricted understanding of the mechanisms underlying species diversity patterns (Vellend 2010) limits our ability to predict and mitigate threats to biodiversity and, further, to ecosystem function (e.g., Urban et al. 2016). A primary goal of community ecology is to elucidate the mechanisms

This article is part of the Topical collection on Basidiomycote Mycology in honor of Franz Oberwinkler who passed away in March 2018

Section Editor: Dominik Begerow

Franz-Sebastian Krah

krah@uni.bio-frankfurt.de; http://orcid.org/0000-0001-7866-7508;

1 Conservation Biology, Institute for Ecology, Evolution and Diversity, Biologicum, Goethe University Frankfurt, Frankfurt am Main, Germany that structure communities along environmental gradients, such as species sorting, biotic interactions, or legacy effects (Vellend 2010). Analyses of functional traits can help to predict community change in response to environmental change across spatial scales. In contrast to fungal community ecology, the use of species traits have a long history in animal and plant community ecology (Grime 2006; Westoby and Wright 2006; Shipley et al. 2016). Trait-based approaches allow an understanding of environmental filters' relative importance and biotic interactions in community assembly (McGill et al. 2006). Today, a large set of tools and methods are available to analyze traits within a community ecological framework (D'Amen et al. 2017; Weiher 2011; de Bello et al. 2021). However, the inclusion of intraspecific trait variability is still rare and a growing body of literature shows that a reliance on means of species trait can lead to (i) an underestimation of intraspecific trait changes, (ii) incorrect inferences regarding the correlations of particular traits with environmental gradients, and (iii) incorrect inferences of assembly processes, e.g., in tests against null-model-based neutral assembly (Jung et al. 
2010; Violle et al. 2012; Bolnick et al. 2011; Fang et al. 2019; Spasojevic et al. 2016; Shipley et al. 2016). Based on a common and widely used method (community mean), we first illustrate how traits can enter a community analysis and demonstrate the effect the consideration of intraspecific trait variability (ITV) can have on inferences based on this method.

\section{Community-fixed versus community-specific trait means}

Although other methods exist to study the link between traits, communities, and the environment (Weiher 2011), the focus here is on the community trait mean as a simple and intuitive mathematical framework with wide applications. After the quantification of species occurrences on plots/sites within a standardized study design, a community matrix is digitalized. To calculate the community trait mean, species traits are assembled (Shipley et al. 2016). Species traits in this framework are typically obtained either from literature or from the measurement of traits during field work. Since the measurement of all individuals is labor-intensive, in plant studies, individuals are often only measured on a few plots to obtain a species trait mean (Shipley et al. 2016). This is especially the case for traits not available from the literature (Shipley et al. 2016). In either case, a fixed, site-independent trait mean of each species is used to calculate community trait means, the "communityfixed mean." Community-fixed mean $(C F M)=\left(\sum_{i=1}^{S} p_{i}{ }_{i}\right)$ $S$, where $p_{i}$ is the proportion (e.g., relative abundance, biomass) of the $i$ th species in a community (site, plot, region, etc.), $S$ is the number of species in that community, and $x_{i}$ is the mean trait (e.g., literature-based species trait) of the $i$ th species (Lepš et al. 2011).

Trait changes along an environmental gradient are thus studied via changes in the community-fixed mean along the gradient and any change in traits is then necessarily attributed to species turnover. However, besides species turnover, trait changes may also or instead reflect intraspecific trait variability (ITV, Fig. 1a) (Lepš et al. 2011), caused by local adaptation or phenotypic plasticity (Bolnick et al. 2011; Violle et al. 2012). To account for ITV, rather than quantifying the community-fixed means, changes in species turnover and ITV are quantified. The field observations and resulting community matrix nonetheless follow a similar approach. Specific, site-dependent traits are measured for individuals on each plot. Thus, in terms of calculating a site-independent community trait mean, a site-dependent community trait mean is calculated (hereafter "community-specific mean"), as Community-specific mean $(C S M)=\frac{\left(\sum_{i=1}^{S} p_{i} x_{i-\text { site }}\right)}{S}$, where $x_{i_{-}}$site is the site-dependent trait value of the ith species on the respective site (Lepš et al. 2011). This individual trait potentially differs for different sites, characterized by different environmental conditions. Note that based on data that allows calculating the community-specific mean, also the community-fixed mean can be obtained by averaging the site-dependent trait values for each species. This approach allows to compare community-fixed with communityspecific means along a gradient and thus to disentangle the relative effects of species turnover and additionally individual trait turnover (e.g., using the R package cati, Taudiere and Violle (2016)).

Many trait-based studies have demonstrated the importance of including ITV in plant community ecology. First, a meta-analysis of 629 plant communities and 36 plant traits revealed that, compared to inter-species variability, the ITV was higher than expected (Siefert et al. 2015). Second, in several studies, the application of community-fixed and specific means showed that trait change is a combined effect of species turnover and intraspecific trait turnover (Jung et al. 2010; Kichenin et al. 2013; Lepš et al. 2011). Moreover, community-specific means can change substantially, independent of a change in the community-fixed means (Kichenin et al. 2013; Jung et al. 2010).

Jung et al. (2010), for example, sampled traits (e.g., specific leaf area or leaf dry matter content) of 20 dominant plant species along an experimental drought gradient (rainfall exclusion), focusing on the strength and direction of the responses of community-fixed and-specific means. They found that in addition to species turnover, there was a large contribution of the intraspecific trait turnover. For some traits (e.g., leaf carbon concentration), there was no effect of the community-fixed mean; however, the specific trait mean responded strongly to drought. The authors concluded that considering community-fixed but not community-specific means leads to an underestimation of responses and probably to erroneous inferences about assembly processes and predictions. As an example, community responses to climate change may not be understood in their full range (Lepš et al. 2011) (Fig. 1b). Therefore, ITV is increasingly being considered in plant community ecology (Jung et al. 2010; Kichenin et al. 2013; Moran et al. 2016; Chalmandrier et al. 2017; Niu et al. 2020), with a growing body of theoretical considerations (Bolnick et al. 2011; Spasojevic et al. 2016; Violle et al. 2012; Albert et al. 2011).

Trait-based approaches have been applied only recently in studies of fungal community ecology, mostly to explore environment-fungi relationships (Aguilar-Trigueros et al. 2015; Crowther et al. 2014; Zanne et al. 2020). Mycelium and spore traits have been studied in Glomeromycota (Munkvold et al. 2004; Ho et al. 2017; Giauque et al. 2019), and mycelium, spore, and fruit body traits in Agaricomycetes (Maynard et al. 2019; Bässler et al. 2016a; Abrego et al. 2016; Krah et al. 2019). Independent of the particular method employed to examine traits within a community ecology framework, to our knowledge, only community-fixed but 
a) Trait change along environmental gradient

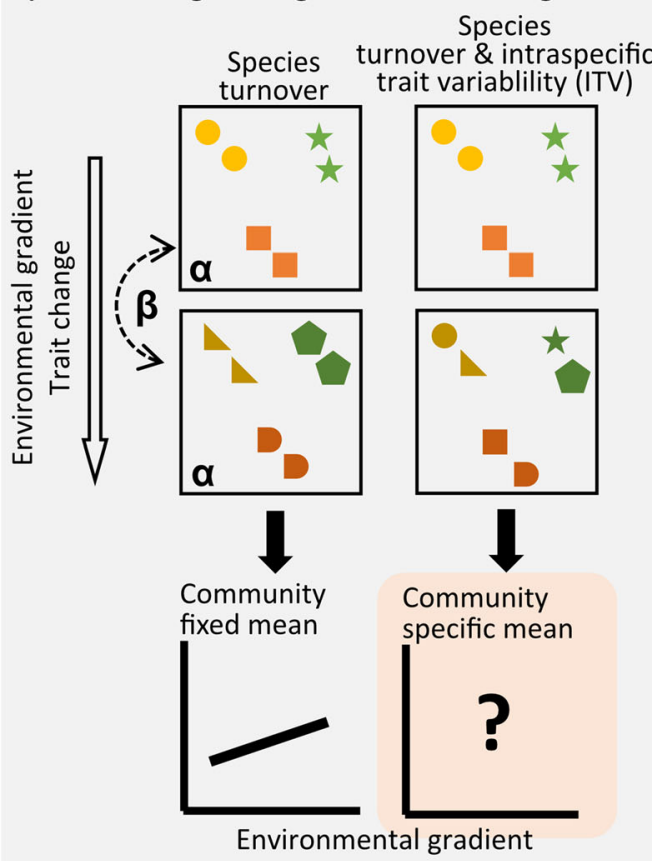

Community fixed mean: Community trait mean calculated from fixed, site-independent trait values (e.g., literature survey) Community specific mean: Community trait mean calculated from specific, site-dependent trait values (in situ measurements)

Fig. 1 Graphical summary of the importance of intraspecific trait variability (ITV) in community ecology studies of macrofungi. a Trait changes along environmental gradients may result from species turnover, individual turnover, or both. We currently do not know the relative importance of species turnover vs. individual trait turnover in macrofungi, limiting our ability to predict and thus mitigate threats to biodiversity, e.g., caused by climate change. b Individual traits may be more extreme than species trait means, thus influencing inferences of assembly processes. For example, even if species shift, individual traits may compensate for lost species traits and thus the community-specific trait mean may not

not community-specific means were applied. We, therefore, briefly review the existing studies of functional traits of macrofungi (fruit body-forming fungi), before demonstrating the importance of incorporating ITV in analyses of community trait means along environmental gradients.

\section{The use of functional traits in community ecology of macrofungi}

Functional traits are increasingly being used to examine the community ecology of macrofungi, but such studies are still rare (Dawson et al. 2018). The majority of studies investigated traits of the sexually reproductive organ (fruit body), e.g., mushroom and spore size. The advantage of focusing on mushroom and spore traits is that they are easily available

\section{b) Expectation when ITV is considered}

Apply null models to adress non-random fixed vs. specific trait averages change

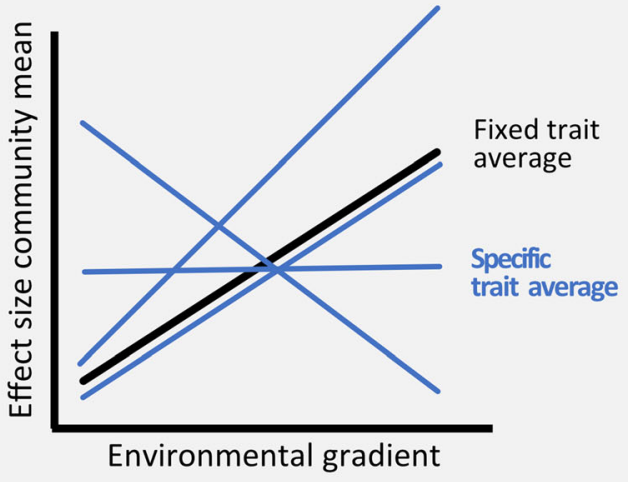

c) Previous studies: fixed average species trait
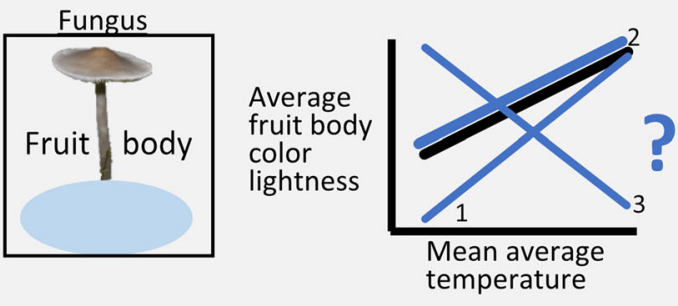

\section{Consequences for predicting trait change e.g., caused by climate warming}

change. c As an example: a previous study used the community-fixed mean of fruit body color lightness, which changed together with the mean average temperature across Europe (Krah et al. 2019). However, since species trait means were used in that study, whether trait change due to species turnover is strengthened, weakened, or neutralized can only be determined by the consideration of ITV (numbers indicate scenarios that are discussed in the main text). Thus, predictions regarding trait changes in response to climate warming may be over- or underestimated when based on community-fixed means alone

because they form an important basis of species identification. Less frequent are studies using mycelium traits, but we are not aware of studies that considered both fruit body and mycelium traits. Investigations of fungal traits have mainly been conducted at a local to landscape scale. Studies addressing fruit body traits showed that the mean fruit body size of assemblages increases with the availability of resources (Bässler et al. 2016a) and that total fruit body biomass is mainly affected by interannual precipitation (Alday et al. 2017). Smaller spores were associated with open shrub-like vegetation and larger spores with forests (Crandall et al. 2020). Forest management was suggested to act as a habitat filter sorting woodinhabiting fungi based on their fruit body characteristics (Bässler et al. 2014), and fruit body size of perennial species was larger in disturbed sites (Bässler et al. 2016b). Resource depletion increased spore elongation of assemblages, 
probably to overcome dispersal limitation (Halbwachs et al. 2017). A study of fruit body types showed differing responses along with a forest management gradient (Abrego et al. 2016). Another study examined multiple traits and found that they correlate with host preferences of wood-inhabiting fungi (Purhonen et al. 2020). In contrast to studies on the local to landscape scale, studies on the continental to global scale are less frequent. Across Norway, species that fruited earlier and more towards continental climates had larger spore size (Kauserud et al. 2011). A study that assessed a variety of reproductive traits (e.g., fruit body and spore size) found that the latitudinal abundance of forest fungi across Great Britain could be predicted by their functional traits (Gange et al. 2018). One study investigated mushroom size globally and found larger mushrooms in temperate and smaller mushrooms in the tropics and boreal zone (Bässler et al. 2021). This effect was attributed to differences in seasonal resource input between biomes or thermoregulation. In a macroclimatic European-scale study, fruit body color lightness was shown to structure the examined fungal communities and followed a mean temperature gradient (Krah et al. 2019). In detail, it was found that mushroom assemblages are darker in cold environments, probably due to thermoregulatory mechanisms (thermal melanism theory). However, there was no evidence of changes in the community-fixed mean color lightness over time (1970-2010), despite expectations that the communities would have already become lighter in response to climate warming ("thermophilization," see Zellweger et al. (2020)). In parallel with the publication of trait-based studies, trait handbooks and guidelines for trait measurement were developed that drew upon plant functional trait frameworks (Dawson et al. 2018; Aguilar-Trigueros et al. 2015; Zanne et al. 2020) and thereby highlighted the importance of studying fungi based on their functional traits (Pringle et al. 2015).

This brief summary of studies and results demonstrates the value of studying fungal traits in a geographic-environmental context as well as their competitive abilities. The important insights provided by the cited studies are, however, limited because we do not know the within-species responses.

\section{How can ITV provide better insights into fungal community ecology?}

The timeline of the above-summarized studies reveals that community ecologists, studying macrofungi, only recently became aware of the advantages of trait-based analyses, in contrast to the much longer history of this approach in plant science. However, as outlined above, interspecific, siteindependent traits are not able to resolve the full spectrum of trait change, i.e., intraspecific trait turnover (Shipley et al. 2016). Although preliminary and based on a small dataset a recent study investigating mushroom size variability found high interspecific variability, demonstrating the potential effect ITV may have on community analysis (Dawson and Jönsson 2020). Thus, we strongly encourage ecologists studying fungal communities to revisit their hypotheses regarding macrofungi, by taking into account ITV and including individual trait measurements in field inventories.

The above example of the community-fixed mean color lightness can be used to illustrate the limitations of approaches based on the fixed community means alone. This example can also be used to demonstrate how to account for ITV in future studies. For example, the color lightness of fungal fruit bodies should be determined for at least three individuals per site per species, such as by taking standardized photos or reflection spectra on all plots across a macroclimatic gradient. Then both a community-fixed (black line in Fig. 1c) and communityspecific trait mean are calculated as described above (blue lines in Fig. 1c).

Based on the inclusion of ITV, three plausible responses of the specific trait mean are proposed as an example, although more are theoretically possible: (1) Individuals in cold climates are darker than mean color trait values, resulting in a more pronounced response of the community-specific mean than of the community-fixed mean. (2) Individual traits do not deviate substantially from the mean lightness trait values and thus, the responses based on the community-fixed and community-specific means are not significantly different. (3) Individual traits deviate strongly from the mean color trait values so that individuals are more light-colored in cold environments and more dark-colored in warm climates. This scenario would lead to a change of the sign of the communityspecific compared to the community-fixed mean (Fig. 1c). As outlined above, Krah et al. (2019) did not find a shift in community-fixed lightness over time, but they did observe a shift in community-fixed lightness with mean annual temperature. One possible explanation may be that species already responded via their intraspecific color lightness, however, not yet via species shifts over time.

\section{Conclusion}

Despite recent recognition of the value of trait-based approaches in community ecology studies of macrofungi (Dawson et al. 2018), the pure focus on species mean trait values to calculate community means may lead to erroneous inferences, interpretations, and predictions of, e.g., the effects of climate change on fungal communities. We, therefore, encourage ecologists studying fungal communities to revise their hypotheses to include ITV in the calculation of community means. Therefore, measuring trait values in situ from a large number of individuals will be necessary in most cases if the retrospective incorporation of ITV into analyses is not possible. 
We suggest a combination of field surveys/experiments with a focus on intraspecific trait values that is complemented by eco-physiological laboratory experiments. Sampling in the laboratory allows traits to be evaluated under standardized conditions. A potential model species for laboratory experiments is the cultivatable and edible mushroom Agrocybe aegerita (Herzog et al. 2019). The above-noted absence of studies simultaneously addressing mycelium and fruit body traits suggests an exciting avenue, especially for future laboratory studies. Finally, although we have discussed the potential pitfalls of ignoring ITV in the context of macrofungal community ecology, the same argument can be made for fungal lineages without conspicuous fruit bodies and/or nonmorphological traits (e.g., molecular traits). The field of fungal community ecology would thus benefit from a unified theoretical concept that incorporates ITV into studies beyond those of macrofungi or morphological traits.

Author contribution FK had the initial idea of the study and wrote the first draft of the manuscript. CB contributed development of the concept and to the writing of the manuscript.

Funding Open access funding enabled and organized by Projekt DEAL.

\section{Declarations}

Availability of data and material (data transparency) Not applicable.

Code availability (software application or custom code) Not applicable.

Competing interests The authors declare that they have no competing interests.

Open Access This article is licensed under a Creative Commons Attribution 4.0 International License, which permits use, sharing, adaptation, distribution and reproduction in any medium or format, as long as you give appropriate credit to the original author(s) and the source, provide a link to the Creative Commons licence, and indicate if changes were made. The images or other third party material in this article are included in the article's Creative Commons licence, unless indicated otherwise in a credit line to the material. If material is not included in the article's Creative Commons licence and your intended use is not permitted by statutory regulation or exceeds the permitted use, you will need to obtain permission directly from the copyright holder. To view a copy of this licence, visit http://creativecommons.org/licenses/by/4.0/.

\section{References}

Abrego N, Norberg A, Ovaskainen O (2016) Measuring and predicting the influence of traits on the assembly processes of wood-inhabiting fungi. J Ecol 105:1070-1081

Aguilar-Trigueros CA, Hempel S, Powell JR, Anderson IC, Antonovics J, Bergmann J, Cavagnaro TR, Chen B, Hart MM, Klironomos J, others (2015) Branching out: towards a trait-based understanding of fungal ecology. Fungal Biology Reviews 29:34-41
Albert CH, Grassein F, Schurr FM, Vieilledent G, Violle C (2011) When and how should intraspecific variability be considered in trait-based plant ecology? Perspectives in Plant Ecology, Evolution and Systematics 13:217-225. https://doi.org/10.1016/j. ppees.2011.04.003

Alday JG, Martínez de Aragón J, de-Miguel S, Bonet JA (2017) Mushroom biomass and diversity are driven by different spatiotemporal scales along Mediterranean elevation gradients. Sci Rep 7:45824. https://doi.org/10.1038/srep45824

Bässler C, Ernst R, Cadotte M, Heibl C, Müller J (2014) Near-to-nature logging influences fungal community assembly processes in a temperate forest. J Appl Ecol 51:939-948

Bässler C, Halbwachs H, Karasch P, Holzer H, Gminder A, Krieglsteiner L, Gonzalez RS, Müller J, Brandl R (2016a) Mean reproductive traits of fungal assemblages are correlated with resource availability. Ecology and evolution 6:582-592

Bässler C, Müller J, Cadotte MW, Heibl C, Bradtka JH, Thorn S, Halbwachs H (2016b) Functional response of lignicolous fungal guilds to bark beetle deforestation. Ecol Indic 65:149-160

Bässler C, Brandl R, Müller J, Krah FS, Reinelt A, Halbwachs H (2021) Global analysis reveals an environmentally driven latitudinal pattern in mushroom size across fungal species. Ecol Lett. https://doi.org/ 10.1111/ele.13678

Bolnick DI, Amarasekare P, Araújo MS, Bürger R, Levine JM, Novak M, Rudolf VHW, Schreiber SJ, Urban MC, Vasseur DA (2011) Why intraspecific trait variation matters in community ecology. R documentation 26:183-192. https://doi.org/10.1016/j.tree.2011.01.009

Chalmandrier L, Münkemüller T, Colace M-P, Renaud J, Aubert S, Carlson BZ, Clément J-C, Legay N, Pellet G, Saillard A, Lavergne S, Thuiller W (2017) Spatial scale and intraspecific trait variability mediate assembly rules in alpine grasslands. J Ecol 105:277-287. https://doi.org/10.1111/1365-2745.12658

Crandall SG, Saarman N, Gilbert GS (2020) Fungal spore diversity, community structure, and traits across a vegetation mosaic. Fungal Ecol 45:100920. https://doi.org/10.1016/j.funeco.2020.100920

Crowther TW, Maynard DS, Crowther TR, Peccia J, Smith JR, Bradford MA (2014) Untangling the fungal niche: the trait-based approach. Front Microbiol 5:579. https://doi.org/10.3389/fmicb.2014.00579

D'Amen M, Rahbek C, Zimmermann NE, Guisan A (2017) Spatial predictions at the community level: from current approaches to future frameworks. Biol Rev 92:169-187. https://doi.org/10. 1111/brv.12222

Dawson SK, Jönsson M (2020) Just how big is intraspecific trait variation in basidiomycete wood fungal fruit bodies? Fungal Ecol 46:100865. https://doi.org/10.1016/j.funeco.2019.100865

Dawson SK, Boddy L, Halbwachs H, Bässler C, Andrew C, Crowther TW, Heilmann-Clausen J, Nordén J, Ovaskainen O, Jönsson M (2018) Handbook for the measurement of macrofungal functional traits: a start with basidiomycete wood fungi. Funct Ecol 33:372387. https://doi.org/10.1111/1365-2435.13239

Bello F de, Carmona CP, Dias ATC, Götzenberger L, Moretti M, Berg MP (2021) Handbook of trait-based ecology: from theory to R tools. Cambridge University Press

Fahrig L (2003) Effects of habitat fragmentation on biodiversity. Annu Rev Ecol Evol Syst 34:487-515. https://doi.org/10.1146/annurev. ecolsys.34.011802.132419

Fang S, Cadotte MW, Yuan Z, Lin F, Ye J, Hao Z, Wang X (2019) Intraspecific trait variation improves the detection of deterministic community assembly processes in early successional forests, but not in late successional forests. J Plant Ecol 12:593-602. https://doi.org/ 10.1093/jpe/rty053

Gange AC, Heegaard E, Boddy L, Andrew C, Kirk P, Halvorsen R, Kuyper TW, Bässler C, Diez J, Heilman-Clausen J, Høiland K, Büntgen U, Kauserud H (2018) Trait-dependent distributional shifts in fruiting of common British fungi. Ecography 41:51-61. https:// doi.org/10.1111/ecog.03233 
Giauque H, Connor EW, Hawkes CV (2019) Endophyte traits relevant to stress tolerance, resource use and habitat of origin predict effects on host plants. The New Phytologist 221:2239-2249. https://doi.org/ 10.1111/nph.15504

Grime JP (2006) Trait convergence and trait divergence in herbaceous plant communities: mechanisms and consequences. J Veg Sci 17: 255-260. https://doi.org/10.1111/j.1654-1103.2006.tb02444.x

Halbwachs H, Heilmann-Clausen J, Bässler C (2017) Mean spore size and shape in ectomycorrhizal and saprotrophic assemblages show strong responses under resource constraints. Fungal Ecol 26:59-64. https://doi.org/10.1016/j.funeco.2016.12.001

Herzog R, Solovyeva I, Bölker M, Lugones LG, Hennicke F (2019) Exploring molecular tools for transformation and gene expression in the cultivated edible mushroom Agrocybe aegerita. Mol Gen Genomics 294:663-677. https://doi.org/10.1007/s00438-01801528-6

Ho W-C, Ohya Y, Zhang J (2017) Testing the neutral hypothesis of phenotypic evolution. PNAS 114:12219-12224. https://doi.org/10. 1073/pnas. 1710351114

Jung V, Violle C, Mondy C, Hoffmann L, Muller S (2010) Intraspecific variability and trait-based community assembly. J Ecol 98:11341140. https://doi.org/10.1111/j.1365-2745.2010.01687.x

Kauserud Hv, Heegaard E, Halvorsen R, Boddy L, H\o iland K, Stenseth NC (2011) Mushroom's spore size and time of fruiting are strongly related: is moisture important? Biol Lett 7:273-276. https://doi.org/ 10.1098/rsbl.2010.0820

Kichenin E, Wardle DA, Peltzer DA, Morse CW, Freschet GT (2013) Contrasting effects of plant inter- and intraspecific variation on community-level trait measures along an environmental gradient. Funct Ecol 27:1254-1261. https://doi.org/10.1111/1365-2435.12116

Krah F-S, Büntgen U, Schaefer H, Müller J, Andrew C, Boddy L, Diez J, Egli S, Freckleton R, Gange AC, Halvorsen R, Heegaard E, Heideroth A, Heibl C, Heilmann-Clausen J, Høiland K, Kar R, Kauserud H, Kirk PM, Kuyper TW, Krisai-Greilhuber I, Norden J, Papastefanou P, Senn-Irlet B, Bässler C (2019) European mushroom assemblages are darker in cold climates. Nat Commun 10:2890. https://doi.org/10.1038/s41467-019-10767-z

Lepš J, de Bello F, Šmilauer P, Doležal J (2011) Community trait response to environment: disentangling species turnover vs intraspecific trait variability effects. Ecography $34: 856-863$. https://doi.org/ 10.1111/j.1600-0587.2010.06904.x

Lindner M, Maroschek M, Netherer S, Kremer A, Barbati A, GarciaGonzalo J, Seidl R, Delzon S, Corona P, Kolström M, Lexer MJ, Marchetti M (2010) Climate change impacts, adaptive capacity, and vulnerability of European forest ecosystems. For Ecol Manag 259: 698-709. https://doi.org/10.1016/j.foreco.2009.09.023

Maynard DS, Bradford MA, Covey KR, Lindner D, Glaeser J, Talbert DA, Tinker PJ, Walker DM, Crowther TW (2019) Consistent tradeoffs in fungal trait expression across broad spatial scales. Nat Microbiol 4:846-853. https://doi.org/10.1038/s41564-019-0361-5

McGill BJ, Enquist BJ, Weiher E, Westoby M (2006) Rebuilding community ecology from functional traits. R documentation 21:178 185. https://doi.org/10.1016/j.tree.2006.02.002

Moran EV, Hartig F, Bell DM (2016) Intraspecific trait variation across scales: implications for understanding global change responses. Glob Chang Biol 22:137-150. https://doi.org/10.1111/gcb.13000

Munkvold L, Kjøller R, Vestberg M, Rosendahl S, Jakobsen I (2004) High functional diversity within species of arbuscular mycorrhizal fungi. New Phytol 164:357-364. https://doi.org/10.1111/j.14698137.2004.01169.x

Niu K, Zhang S, Lechowicz MJ (2020) Harsh environmental regimes increase the functional significance of intraspecific variation in plant communities. Funct Ecol. https://doi.org/10.1111/1365-2435.13582

Norros V, Karhu E, Nordén J, Vähätalo AV, Ovaskainen O (2015) Spore sensitivity to sunlight and freezing can restrict dispersal in wooddecay fungi. Ecology and evolution 5:3312-3326
Pringle A, Vellinga E, Peay K (2015) The shape of fungal ecology: does spore morphology give clues to a species' niche? Fungal Ecol:213-216

Purhonen J, Ovaskainen O, Halme P, Komonen A, Huhtinen S, Kotiranta H, Læssøe T, Abrego N (2020) Morphological traits predict hosttree specialization in wood-inhabiting fungal communities. Fungal Ecol 46:100863. https://doi.org/10.1016/j.funeco.2019.08.007

Shipley B, de Bello F, Cornelissen JHC, Laliberté E, Laughlin DC, Reich PB (2016) Reinforcing loose foundation stones in traitbased plant ecology. Oecologia 180:923-931. https://doi.org/10. 1007/s00442-016-3549-x

Siefert A, Violle C, Chalmandrier L, Albert CH, Taudiere A, Fajardo A, Aarssen LW, Baraloto C, Carlucci MB, Cianciaruso MV, de Dantas VL, de Bello F, LDS D, Fonseca CR, Freschet GT, Gaucherand S, Gross N, Hikosaka K, Jackson B, Jung V, Kamiyama C, Katabuchi M, Kembel SW, Kichenin E, NJB K, Lagerström A, Le BagoussePinguet Y, Li Y, Mason N, Messier J, Nakashizuka T, Overton JM, Peltzer DA, Pérez-Ramos IM, Pillar VD, Prentice HC, Richardson S, Sasaki T, Schamp BS, Schöb C, Shipley B, Sundqvist M, Sykes MT, Vandewalle M, Wardle DA (2015) A global meta-analysis of the relative extent of intraspecific trait variation in plant communities. Ecol Lett 18:1406-1419. https://doi.org/10.1111/ele.12508

Spasojevic MJ, Turner BL, Myers JA (2016) When does intraspecific trait variation contribute to functional beta-diversity? J Ecol 104: 487-496. https://doi.org/10.1111/1365-2745.12518

Taudiere A, Violle C (2016) cati: an R package using functional traits to detect and quantify multi-level community assembly processes. Ecography 39:699-708. https://doi.org/10.1111/ecog.01433

Urban MC, Bocedi G, Hendry AP, Mihoub J-B, Pe'er G, Singer A, Bridle JR, Crozier LG, de Meester L, Godsoe W, Gonzalez A, Hellmann JJ, Holt RD, Huth A, Johst K, Krug CB, Leadley PW, Palmer SCF, Pantel JH, Schmitz A, Zollner PA, Travis JMJ (2016) Improving the forecast for biodiversity under climate change. Science:353. https:// doi.org/10.1126/science.aad8466

Vellend M (2010) Conceptual synthesis in community ecology. Q Rev Biol 85:183-206

Violle C, Enquist BJ, McGill BJ, Jiang L, Albert CH, Hulshof C, Jung V, Messier J (2012) The return of the variance: intraspecific variability in community ecology. Trends Ecol Evol 27:244-252. https://doi. org/10.1016/j.tree.2011.11.014

Weiher E (2011) A primer of trait and functional diversity. Biological diversity: frontiers in measurement and assessment:175-193

Westoby M, Wright IJ (2006) Land-plant ecology on the basis of functional traits. $\mathrm{R}$ documentation 21:261-268. https://doi.org/10.1016/ j.tree.2006.02.004

Zanne AE, Abarenkov K, Afkhami ME, Aguilar-Trigueros CA, Bates S, Bhatnagar JM, Busby PE, Christian N, Cornwell WK, Crowther TW, Flores-Moreno H, Floudas D, Gazis R, Hibbett D, Kennedy P, Lindner DL, Maynard DS, Milo AM, Nilsson RH, Powell J, Schildhauer M, Schilling J, Treseder KK (2020) Fungal functional ecology: bringing a trait-based approach to plant-associated fungi. Biol Rev 95:409-433. https://doi.org/10.1111/brv.12570

Zellweger F, de Frenne P, Lenoir J, Vangansbeke P, Verheyen K, Bernhardt-Römermann M, Baeten L, Hédl R, Berki I, Brunet J, van Calster H, Chudomelová M, Decocq G, Dirnböck T, Durak T, Heinken T, Jaroszewicz B, Kopecký M, Máliš F, Macek M, Malicki M, Naaf T, Nagel TA, Ortmann-Ajkai A, Petř́k P, Pielech R, Reczyńska K, Schmidt W, Standovár T, Świerkosz K, Teleki B, Vild O, Wulf M, Coomes D (2020) Forest microclimate dynamics drive plant responses to warming. Science 368:772-775. https://doi. org/10.1126/science.aba6880

Publisher's note Springer Nature remains neutral with regard to jurisdictional claims in published maps and institutional affiliations. 